\title{
Relationship of Acute Phase Reactants and Fat Accumulation during Treatment for Tuberculosis
}

\author{
Alejandro Sanchez, Colleen Azen, Brenda Jones, Stan Louie, and Fred Sattler \\ Division of Infectious Diseases, Department of Medicine, The Keck School of Medicine and the School of Pharmacy of the University of \\ Southern California, IRD Building, Room 432, 2020 Zonal Avenue, Los Angeles, CA 90033, USA \\ Correspondence should be addressed to Alejandro Sanchez, asanchez@usc.edu
}

Received 2 June 2011; Accepted 3 July 2011

Academic Editor: S. G. Franzblau

Copyright ( $) 2011$ Alejandro Sanchez et al. This is an open access article distributed under the Creative Commons Attribution License, which permits unrestricted use, distribution, and reproduction in any medium, provided the original work is properly cited.

Background. Tuberculosis causes inflammation and muscle wasting. We investigated how attenuation of inflammation relates to repletion of body composition during treatment in an underserved population. Design. Twenty-four patients (23 to 79 years old) with pulmonary tuberculosis and inflammation (pretreatment albumin $=2.96 \pm 0.13 \mathrm{~g} / \mathrm{dL}$, C-reactive protein [CRP] $=$ $6.71 \pm 1.34 \mu \mathrm{g} / \mathrm{dL}$, and beta-2-microglobulin $=1.68 \pm 0.10 \mu \mathrm{g} / \mathrm{L})$ were evaluated and had BIA over 24 weeks. Results. Weight increased by $3.02 \pm 0.81 \mathrm{~kg}(5.5 \% ; P=0.007)$ at week 4 and by $8.59 \pm 0.97 \mathrm{~kg}(15.6 \% ; P<0.0001)$ at week 24 . Repletion of body mass was primarily fat, which increased by $2.09 \pm 0.52 \mathrm{~kg}$ at week 4 and $5.05 \pm 0.56 \mathrm{~kg}$ at week $24(P=0.004$ and $P<0.0001$ versus baseline). Fat-free mass (FFM), body cell mass (BCM), and phase angle did not increase until study week 8 . Albumin rose to $3.65 \pm 0.14 \mathrm{~g} / \mathrm{dL}$ by week $4(P<0.001)$ and slowly increased thereafter. CRP levels declined by $\sim 50 \%$ at each interval visit. Conclusions. During the initial treatment, acute phase reactants returned towards normal. The predominant accrual of fat mass probably reflects ongoing, low levels of inflammation.

\section{Introduction}

Tuberculosis remains one of the most common infections in the world and causes substantial morbidity and mortality. Poor outcomes often relate to severe inflammation and reduced intake of energy and protein that may advance to overt cachexia (protein calorie malnutrition) $[1,2]$. As with other systemic inflammatory conditions (e.g., sepsis, burns, massive trauma), proinflammatory cytokines are presumed to orchestrate the release of amino acids from preformed pools in skeletal muscle and breakdown of myofibrillar proteins (acute phase reaction) [3]. These amino acids are transported to the liver and there provide the metabolic fuel for gluconeogenesis and synthesis of new proteins for white cells to combat infection and repair damaged tissue [3], as would occur with tuberculosis. Further, appetite is suppressed during inflammation by TNF $\alpha$ [4] and thus ingestion of sufficient nutrients may not occur, even if food is accessible.
In patients with lean tissue wasting due to chronic hepatitis, renal failure, or AIDS, providing supplemental energy leads to weight gain that is primarily associated with accrual of fat mass with relatively little improvement in lean mass or functional performance [5-8]. It can be speculated that accrual of primary fat mass is the result of ongoing inflammation in those conditions. There is little information available about the quantity and type of body composition repletion during treatment of tuberculosis and how it relates to inflammation $[1,2,9,10]$. We hypothesized that treatment of tuberculosis, even without supplemental nutrition, would suppress markers of inflammation and improve body mass that would include a substantial portion of new lean tissue, unlike what occurs with nutritional repletion during ongoing inflammation (i.e., primarily fat accrual) in other chronic catabolic disorders. We, therefore, conducted a prospective study to characterize the timing of changes in inflammation as measured by acute phase reactants and their relationship to improvements in body composition during treatment 
of tuberculosis in an underserved inner city population. Understanding these relationships will be important in developing strategies to substantially augment lean tissue mass, which in general is correlated with enhanced physical function and improved quality of life $[11,12]$.

\section{Methods}

2.1. Study Design. The study was a prospective investigation designed to assess changes in body composition and markers of inflammation during treatment of pulmonary tuberculosis in HIV-negative patients.

2.2. Patient Selection. Daily reports of positive sputum smears for acid-fast bacteria generated by the Clinical Microbiology Laboratory of the Los Angeles County-University of Southern California (LAC-USC) Medical Center were used to identify potential study participants. Patients with clinical characteristics and pulmonary radiographs consistent with acute pulmonary tuberculosis were invited to participate. Each signed an informed consent approved by the IRB at USC before enrollment or testing.

2.3. Eligibility Criteria. Inclusion criteria required that patients be $\geq 18$ years of age with presence of a positive sputum showing acid-fast bacteria and later confirmed by growth of Mycobacterium tuberculosis in culture, less than 96 hours of antituberculosis therapy, negative HIV serology, alanine aminotransferase level less than five times the upper limit of normal, total serum bilirubin $\leq 2.0 \mathrm{mg} / \mathrm{dL}$, white blood cell count $\geq 3000$ cells $/ \mu \mathrm{L}$, and platelets $\geq 70,000$ cells $/ \mu \mathrm{L}$. Patients were treated with isoniazid, rifampin, pyrazinamide, and ethambutol for the first two months and isoniazid and rifampin thereafter in accordance to the United States Centers for Disease Control $\&$ Prevention and American Thoracic Society guidelines.

2.4. Outcomes. All participants were examined by a study physician, had body composition measured and laboratory testing at baseline and study weeks 4, 8, 16 and 24. Blood was tested for complete blood counts, serum chemistries, Creactive protein (CRP), beta-2-microglobulin, and albumin in the LAC-USC Clinical Laboratory.

2.5. Body Composition. Body composition measures included height using a stadiometer and weight on the same calibrated scales with participants in underwear and gown. Fat-free mass (FFM), fat mass, body cell mass (BCM), and phase angle were determined by single frequency bioelectrical impedance analysis (BIA; RJL Quantum, Clinton Township, Michigan). For BIA, tests were conducted by a single study nurse certified in electrode placement and body positioning during training at AIDS Clinical Trials Group meetings. Fat, FFM, and BCM were calculated using published equations validated previously in wasted and nutritionally replete patients [13].
TABLE 1: Baseline characteristics of study participants.

\begin{tabular}{lc}
\hline No. of patients & 24 \\
Age $y e a r{ }^{*}$ & $42 \pm 3.06(23-79)$ \\
Male : female & $16: 8$ \\
Ethnicity & 20 \\
$\quad$ Hispanic & 1 \\
$\quad$ Non-Hispanic White & 2 \\
$\quad$ Non-Hispanic Black & 1 \\
$\quad$ Asian-Pacific Islander & $55.8 \pm 2.45(34.3-73.9)$ \\
Total body mass (weight) kg & $24.5 \pm 0.96(16.8-28.8)$ \\
Body mass index kg/m ${ }^{2}$ & $45.7 \pm 2.43(29.77-72.04)$ \\
Fat-free mass kg & $9.2 \pm 1.78(-0.8-29.14)$ \\
Fat mass kg & $46.8 \pm 2.93(24.3-70.7)$ \\
Body cell mass kg & $6.03 \pm 0.35(3.3-9.1)$ \\
Phase angle & $2.96 \pm 0.13(1.8-4.5)$ \\
Serum albumin $\mathrm{g} / \mathrm{dL}$ & $6.71 \pm 1.34(1.4-19.4)$ \\
C-reactive protein $\mu \mathrm{g} / \mathrm{L}$ & $1.68 \pm 0.10(1.0-2.5)$ \\
Beta-2-microglobulin $\mu \mathrm{g} / \mathrm{L}$ &
\end{tabular}

${ }^{*}$ mean \pm standard error (range).

2.6. Statistical Analysis. For measures of body composition and inflammatory markers (acute phase reactants), patterns of change from baseline over time were analyzed using a repeated measures mixed model for each outcome variable, with weeks as a fixed effect and participants as a random effect, and unstructured covariance. Unless indicated in footnotes, mean values are reported with variance as standard errors, based on estimates generated by the mixed model analyses. Adjusted $P$ values were calculated for comparing differences between estimated least squares means at baseline and each of the subsequent time points, or between two adjacent time points. The relationships between total change at 24 weeks in various measures were examined with Pearson correlation coefficients. Two sided $P$ values $<0.05$ were considered statistically significant.

\section{Results}

3.1. Study Participants. Twenty-four consecutive patients meeting eligibility criteria were enrolled. Four participants withdrew from study after the initial baseline examination (two lost to follow up and two refused further blood draws). Diagnosis of M. tuberculosis was presumed in all participants based on sputum smears showing acid fast bacteria and chest radiographs consistent with tuberculosis. Sputum cultures confirmed the presence of $M$. tuberculosis in each case using standard laboratory methods in a Los Angeles County Public Health reference laboratory. None of the participants received nutritional supplementation during therapy for their tuberculosis.

Table 1 shows that participants were largely ethnic minorities and their ages ranged from 23 to 79 years. Their BMI was $24.5 \pm 0.96 \mathrm{~kg} / \mathrm{m}^{2}$ and indicated that they were not severely malnourished but their low albumin and elevated 


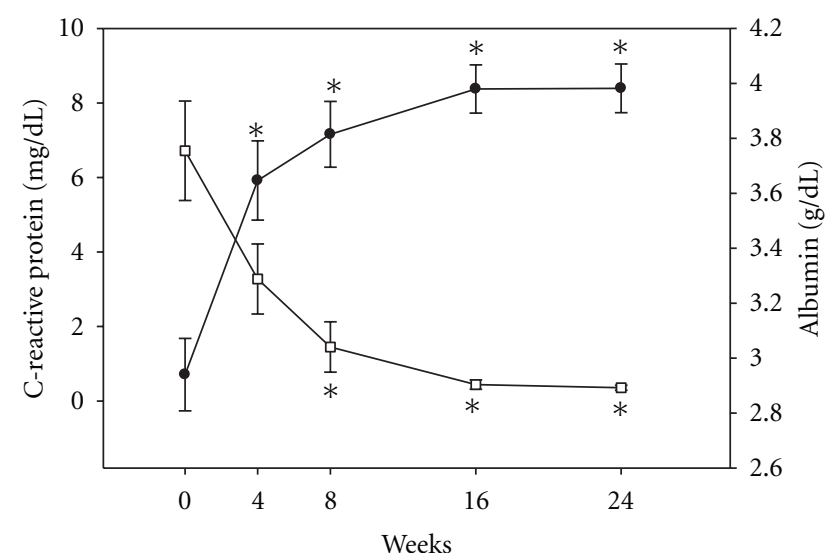

FIGURE 1: Serum C-reactive protein and albumin during treatment. Figure shows the change C-reactive protein (CRP, open squares) and albumin (filled circles) at each time point compared to baseline. There was an inverse relationship between serum albumin and CRP. * represents significant changes $(P<0.05)$ compared to baseline (week 0); whiskers are standard errors and for CRP at weeks 16 and 24 are small and not be demonstrable on figure.

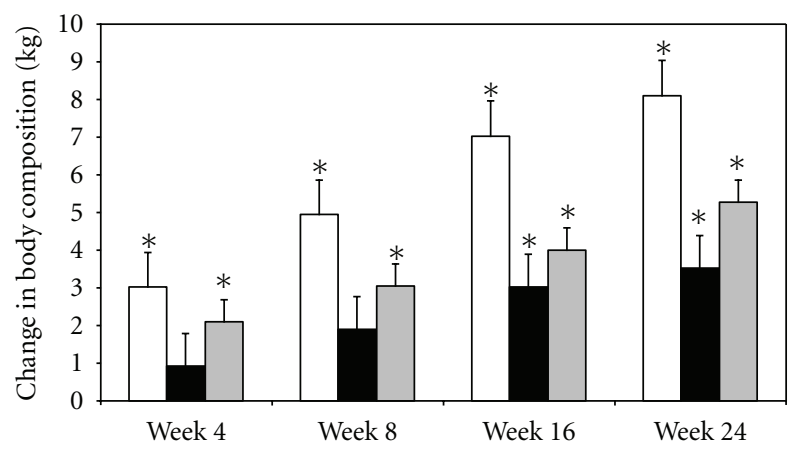

Figure 2: Change in body mass. The change in weight is shown by open bars and fat-free mass by black bars and fat mass by gray bars at each time point compared to baseline. Whiskers represent standard errors. * represent significant change $(P<0.05)$ compared to baseline.

CRP and beta-2-microglobulin levels reflected that there was substantive inflammation when treatment was initiated.

3.2. Acute Phase Reactants. Pretreatment serum albumin was $2.96 \pm 0.13 \mathrm{~g} / \mathrm{dL}$, well below the normal range; levels increased briskly to $3.65 \pm 0.14 \mathrm{~g} / \mathrm{dL}(P<0.001)$ by study week 4 and reached a plateau by study week 8 (3.82 \pm $0.12 \mathrm{~g} / \mathrm{dL} ; P=0.28$ versus week 4 , Figure 1$)$. There was a reciprocal relationship between serum albumin and CRP. At baseline, CRP levels were elevated $(6.71 \pm 1.34 \mu \mathrm{g} / \mathrm{dL})$ but declined by more than $50 \%$ at weeks 4,8 , and 16 and reached normal values by weeks 16 and $24(0.44 \pm 0.12$ and $0.35 \pm$ $0.067 \mu \mathrm{g} / \mathrm{dL}$, resp.); levels were nearly different at week $4(P=$ $0.061)$ and significantly different than baseline at the weeks $8,16$, and 24 ( $P=0.004, P=0.0007$, and $P=0.0007$, resp. $)$. Beta-2-microglobulin increased at week 4 and then followed

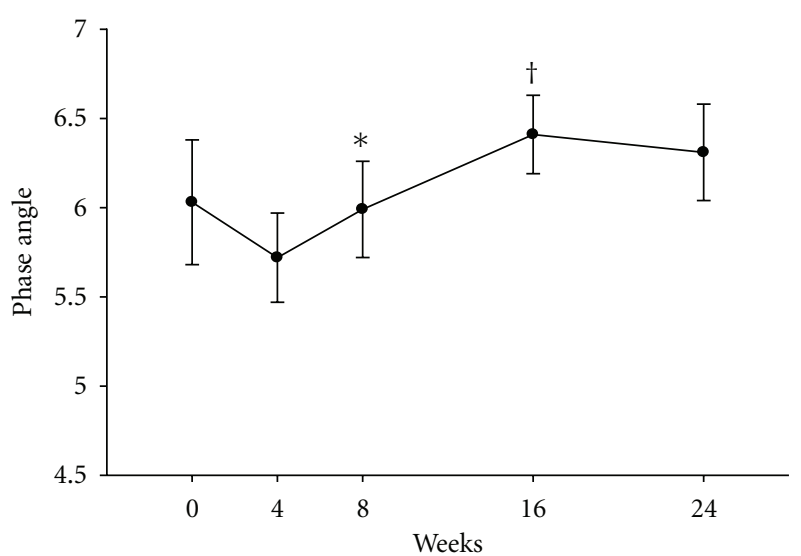

Figure 3: Phase angle during treatment. Average phase angle (shown on $Y$ axis) by bioelectrical impedance analysis at each study week. ${ }^{*} P=0.005$ compared to week 4 . Whiskers represent standard errors. ${ }^{\dagger} P=0.01$ compared to week 8 .

a similar pattern of change to CRP (data not shown since there was a collinear relationship between the two for change over 24 weeks; $r=0.70, P=0.002$ ).

3.3. Body Composition. Figure 2 shows absolute change in total body mass, FFM, and fat mass. By study week 4, participants average weight increased by $3.02 \pm 0.81 \mathrm{~kg}(P$ $=0.007)$ that continued to improve at weeks 8 and 16, and by week 24 was $8.59 \pm 0.97 \mathrm{~kg}(P<0.0001)$ greater than baseline (Table 2). These improvements in weights represented relative increases of $5.5 \%$ to $15.6 \%$ from weeks 4 through 24, respectively. FFM also increased continuously over the 24 weeks (Figure 2) but changes from baseline did not reach statistical significance until study weeks 16 and 24 with absolute improvements of $3.02 \pm 0.80 \mathrm{~kg}(P=0.007)$ and $3.53 \pm 0.78 \mathrm{~kg}(P=0.002)$, respectively, compared to baseline (Table 2). Fat mass also increased with absolute increments of $2.09 \pm 0.52 \mathrm{~kg}$ to $5.05 \pm 0.56 \mathrm{~kg}$ through week 24 with changes at each of the interval visits that were significantly different than baseline $(P=0.004$ to $<0.0001)$.

BCM increased in parallel to FFM, with significant increases over baseline at 16 and 24 weeks of $4.00 \pm 0.84 \mathrm{~kg}$ and $4.64 \pm 0.93 \mathrm{~kg}(P=0.001$ and $P=0.0005)$, respectively (Table 2). Further, low phase angle, an important indicator of malnutrition and poor clinical outcomes, decreased from baseline to week 4 but increased thereafter (Figure 3) with statistically significant improvements at weeks 8 and 16 compared to the prior week $(0.27 \pm 0.07$ and $0.42 \pm 0.11$, $P=0.005$ and 0.01 , resp.) [14].

Table 3 shows the relationships between change in weight, body composition, and acute phase reactants. In brief, as albumin levels increased, this was associated with improvements in total weight and changes in all three acute phases reactants (albumin, CRP, and beta-2-microglobulin) were related to changes in fat mass. Changes in BCM were associated with changes in weight and FFM. 
TABLE 2: Changes in body composition during treatment.

\begin{tabular}{|c|c|c|c|c|c|}
\hline Change in body composition & Week 4 & Week 8 & Week 16 & Week 24 & $P$ value ANOVA \\
\hline \multirow{2}{*}{ Weight kg } & $3.02 \pm 0.81^{*, a}$ & $4.94 \pm 1.08^{\mathrm{a}, \mathrm{b}}$ & $7.03 \pm 0.97^{\mathrm{b}, \mathrm{c}}$ & $8.59 \pm 0.97^{c}$ & $<0.0001$ \\
\hline & $5.5 \% * *$ & $9.0 \%$ & $12.8 \%$ & $15.6 \%$ & \\
\hline \multirow{2}{*}{ Fat-free mass kg } & $0.93 \pm 0.78^{a}$ & $1.90 \pm 0.95^{\mathrm{a}, \mathrm{b}}$ & $3.02 \pm 0.80^{\mathrm{b}, *}$ & $3.53 \pm 0.78$ & $<0.0001$ \\
\hline & $2.0 \%$ & $4.2 \%$ & $6.6 \%$ & $7.7 \%$ & \\
\hline \multirow{2}{*}{ Body cell mass kg } & $0.02 \pm 0.95^{\mathrm{a}}$ & $1.65 \pm 1.02^{\mathrm{a}, \mathrm{b}}$ & $4.00 \pm 0.84^{\mathrm{b}, *}$ & $4.64 \pm 0.93$ & $<0.0001$ \\
\hline & $0.0 \%$ & $3.5 \%$ & $8.5 \%$ & $9.9 \%$ & \\
\hline \multirow{2}{*}{ Fat mass $\mathrm{kg}$} & $2.09 \pm 0.52^{*, \mathrm{a}}$ & $3.04 \pm 0.50^{\mathrm{a}}$ & $4.00 \pm 0.59^{\mathrm{b}}$ & $5.05 \pm 0.56^{\mathrm{b}}$ & $<0.0001$ \\
\hline & $22.7 \%$ & $33.1 \%$ & $43.5 \%$ & $55.0 \%$ & \\
\hline
\end{tabular}

* different at time point compared to baseline $(P<0.05)$; variance $( \pm)$ is standard error.

$* *$ percent change is the ratio of the absolute increase at study week divided by the baseline value $\times 100$.

a,b,c values with same superscript ("a" and "a") are significantly different (adjusted $P<0.05$ ) in pairwise comparisons.

TABLE 3: Relationships of change in weight, body composition, and acute phase reactants.

\begin{tabular}{lccccc}
\hline & \multicolumn{2}{c}{ Change in weight* } & \multicolumn{2}{c}{ Change in fat-free mass } & \multicolumn{2}{c}{ Change in fat mass } \\
& Pearson $R$ value & $P$ value & Pearson $R$ value & $P$ value & Pearson $R$ value \\
\hline Change in albumin* & 0.58 & 0.01 & 0.21 & 0.42 & 0.59 \\
Change in C-reactive protein & -0.23 & 0.41 & 0.19 & 0.49 & -0.58 \\
Change in beta-2-microglobulin & -0.03 & 0.93 & 0.36 & 0.19 & -0.50 \\
Change in body cell mass & 0.66 & 0.004 & 0.73 & 0.0008 & 0.02 \\
Change in phase angle & 0.13 & 0.61 & -0.06 & 0.83 & 0.051 \\
\hline
\end{tabular}

*changes in body composition parameters and acute phase reactants from baseline to study week 24 .

\section{Discussion}

Our study is unique and the first to report changes in acute phase reactants (albumin, CRP, and beta-2-microglobulin) as measures of inflammation and how their levels relate to repletion of body composition components during treatment of tuberculosis. In brief, albumin levels increased quickly by week 4 of treatment and then more slowly thereafter. There were reciprocal decreases in CRP and beta2-microglobulin, but those occurred somewhat more slowly and did not reach significance until week 8 for CRP and week 24 for beta-2-microglobulin. In this context, total body mass increased briskly by $\sim 3 \mathrm{~kg}$ at study week 4 and continued to increase each month thereafter. By study week 24 , participants had gained $\sim 8.6 \mathrm{~kg}$ ( $15.6 \%$ increase), thereby demonstrating the effects of treating infection per se and suppressing inflammation on restoring body mass. These robust changes in this underserved population occurred during habitual eating of available foods without nutritional supplementation.

The rate and magnitude of these improvements in total mass are greater than reported in developing countries $(<10 \%$ in six months) or in persons coinfected with HIV [5, $15,16]$. It may be that in developing countries there is greater food insecurity and with coinfections (e.g., HIV, parasites), there is continued infection and inflammation, both of which could dampen repletion of body mass. Regardless, demonstrating the feasibility of rapid and substantive weight repletion soon after initiating treatment without nutritional supplementation is of importance since tuberculosis complicated by cachexia is associated with an increased risk of death $[17,18]$.

The composition of the changes in body mass was not as we hypothesized. FFM did not improve significantly until study week 8 with increases just under $2 \mathrm{~kg}(\sim 40 \%$ of increase in total mass) and only modestly increased $\sim 3 \mathrm{~kg}(\sim 43 \%)$ at week 16 without further increases at week 24. This was unexpected based on brisk improvement in acute phase reactants in the first two months suggesting that inflammation was quickly attenuated during treatment. However, in the only other report in the modern era that measured components of body composition in patients only infected with tuberculosis, Schwenk and colleagues also showed blunted improvements in FFM with no increases in FFM after one month of treatment with improvements of only $1.5 \mathrm{~kg}$ after six months [5]. In our study, fat mass increased significantly by $\sim 2 \mathrm{~kg}$ at week 4 and then by $\sim 1 \mathrm{~kg}$ per month until week 24 ( $\sim 5 \mathrm{~kg}$ total increase), and across these time points accounted for almost two-thirds of the increases in total mass in our patients. Similarly, Schwenk and colleagues demonstrated that patients gained 10\% in body weight after six months of treatment, and this was almost entirely fat mass [5]. We can only speculate that accrual of largely fat mass in both studies was due to ongoing low-grade inflammation as occurs in other chronic catabolic disorders. In fact, there was still evidence of inflammation during the last 3 months of treatment when levels of CRP and beta-2-microglobulin were just beginning to plateau. 
Macronutrient and total energy intake, which we did not measure, may have affected outcomes as well. During catabolism in sepsis and burns, feeding excess calories has resulted in increasing energy expenditure and futile utilization of fuel with resultant fat deposition without increasing lean mass [19-22]. Our participants were largely underserved and we did not assess quantity or quality of calories that they consumed, which may have been predominantly fat or carbohydrate (not protein) during treatment and attenuation of inflammation. Indeed, even high energy nutritional supplementation administered within two weeks of starting treatment for tuberculosis was associated with primarily accrual of fat mass [9]. During chronic renal failure, patients had to receive protein intakes of about 1.5$2 \mathrm{~g} / \mathrm{kg} /$ day (twofold or greater than the recommended daily allowance for protein) to achieve positive nitrogen balance [23-26]. We, therefore, speculate that providing optimized dietary protein during treatment of catabolic disorders such as tuberculosis, as with renal failure, is likely to be important in repleting lean tissue, especially BCM, but this remains to be determined $[9,27,28]$.

Changes in two other BIA derived parameters may be useful measurements in assessing risk for poor outcomes and monitoring therapy in catabolic disorders such as tuberculosis. BCM when quantified by total body potassium content is reflective of the metabolically active cell fraction of total body mass and relates closely with survival [17, 29]. Improvement in BCM, as occurred in our participants, has been associated with improved outcomes [29-31]. However, $\mathrm{BCM}$, a mathematical derivation from FFM when measured by BIA, was indeed closely linked to changes in weight and FFM in our study, and thus provides little information beyond expected benefits reflective of improvements in FFM. By contrast, the phase angle between resistance and reactance as measured by BIA is a marker of cell integrity and is useful to quantify malnutrition and may be superior to other markers such as BCM, BMI, serum, albumin, cholesterol, and so forth, [14, 17, 32]. Indeed, improvements in phase angle have been associated with better clinical outcomes including survival in patients with HIV [14,33]. Phase angle increased significantly after an initial decline during therapy in our study. Our participants, who were HIV negative, were alive and free living after six months of therapy. Regardless, improvements in BCM and phase angle after the first month of therapy generally paralleled improvements in body mass, FFM, and acute phase reactants. These findings suggest that BIA may be a useful methodology to monitor body composition, nutritional status, and effects of therapy in more severely ill patients especially in resource limited settings where quantifying lean mass by dual energy $X$ ray absorptiometry or other imaging modalities, access to skilled dietary counseling or anthropometric measurements, and even routine laboratory tests of malnutrition and inflammation are not readily available.

There are limitations with BIA. FFM is derived mathematically from complex equations that assume the body is a cylinder, and fat mass is the difference of total mass (weight) minus FFM. The methodology should be validated against more rigorous measures in different populations with different baseline morphologic characteristics. Formulas may have to be modified in these populations. In addition, surface electrodes must be properly and reproducibly placed, but training is relatively straight forward and quick. Further, weight needs to be measured in a controlled manner with patients lightly clothed (e.g., gown and underwear) using the same scales periodically calibrated. Finally, height must be carefully determined, which is best done with a stadiometer during proper positioning and should only be measured once since it is squared in formulas for FFM and small variations due to positioning may affect readouts. Regardless, BIA has proven useful in studying and monitoring patients with wasting and should be a cost effective and convenient method to assess nutritional status and body composition in developing countries.

In conclusion, treatment of tuberculosis resulted in prompt and progressive suppression of inflammation with sizable repletion of body mass after only six months of therapy. However, increases in weight were associated primarily with accrual of fat mass despite an apparent rapid attenuation in inflammation based on changes in acute phase reactants. We speculate that to achieve accrual of larger portion of lean tissue and metabolically active body cell mass during treatment may require dietary supplementation with high biologic quality protein or other strategies to improve nutrition or further suppress inflammation. Regardless, findings from this study should have important ramifications for designing future research trials and for treatment of tuberculosis in underserved inner city populations and in developing countries, especially for patients who are cachectic and where there may be food insecurity.

\section{Authors' Contribution}

We attest to the fact that all authors listed have read and approved the manuscript, attest to the validity, and legitimacy of the data and its interpretation, and agree to its submission. All corresponding authors have contributed to the preparation of the paper, and no other person or persons other than the authors listed have contributed to its preparation.

\section{Acknowledgments}

The authors gratefully acknowledge the contribution of the research coordinator, Claudia Trigo, and data manager, Maria Brown, and the patients without whom this study would not have been possible.

\section{References}

[1] M. van Lettow, J. W. van der Meer, C. E. West, R. van Crevel, and R. D. Semba, "Interleukin-6 and human immunodeficiency virus load, but not plasma leptin concentration, predict anorexia and wasting in adults with pulmonary tuberculosis in Malawi," Journal of Clinical Endocrinology and Metabolism, vol. 90, no. 8, pp. 4771-4776, 2005. 
[2] N. I. Paton and Y. M. Ng, "Body composition studies in patients with wasting associated with tuberculosis," Nutrition, vol. 22, no. 3, pp. 245-251, 2006.

[3] C. Gabay and I. Kushner, "Acute-phase proteins and other systemic responses to inflammation," The New England Journal of Medicine, vol. 340, no. 6, pp. 448-454, 1999.

[4] H. R. Michie, M. L. Sherman, D. R. Spriggs, J. Rounds, M. Christie, and D. W. Wilmore, "Chronic TNF infusion causes anorexia but not accelerated nitrogen loss," Annals of Surgery, vol. 209, no. 1, pp. 19-24, 1989.

[5] A. Schwenk, L. Hodgson, A. Wright et al., "Nutrient partitioning during treatment of tuberculosis: gain in body fat mass but not in protein mass," The American Journal of Clinical Nutrition, vol. 79, no. 6, pp. 1006-1012, 2004.

[6] D. P. Kotler, A. R. Tierney, J. A. Culpepper-Morgan, J. Wang, and R. N. Pierson Jr., "Effect of home total parenteral nutrition on body composition in patients with acquired immunodeficiency syndrome," Journal of Parenteral and Enteral Nutrition, vol. 14, no. 5, pp. 454-458, 1990.

[7] D. P. Kotler, A. R. Tierney, R. Ferraro, P. Cuff, R. N. Pierson Jr., and S. B. Heymsfield, "Enteral alimentation and repletion of body cell mass in malnourished patients with acquired immunodeficiency syndrome," The American Journal of Clinical Nutrition, vol. 53, no. 1, pp. 149-154, 1991.

[8] J. Axelsson, A. R. Qureshi, M. E. Suliman et al., "Truncal fat mass as a contributor to inflammation in end-stage renal disease," The American Journal of Clinical Nutrition, vol. 80, no. 5, pp. 1222-1229, 2004.

[9] N. I. Paton, Y. K. Chua, A. Earnest, and C. B. Chee, "Randomized controlled trial of nutritional supplementation in patients with newly diagnosed tuberculosis and wasting," The American Journal of Clinical Nutrition, vol. 80, no. 2, pp. 460-465, 2004.

[10] E. Villamor, E. Saathoff, F. Mugusi, R. J. Bosch, W. Urassa, and W. W. Fawzi, "Wasting and body composition of adults with pulmonary tuberculosis in relation to HIV-1 coinfection, socioeconomic status, and severity of tuberculosis," European Journal of Clinical Nutrition, vol. 60, no. 2, pp. 163-171, 2006.

[11] R. Mostert, A. Goris, C. Weling-Scheepers, E. F. Wouters, and A. M. Schols, "Tissue depletion and health related quality of life in patients with chronic obstructive pulmonary disease," Respiratory Medicine, vol. 94, no. 9, pp. 859-867, 2000.

[12] G. J. Wagner, S. J. Ferrando, and J. G. Rabkin, "Psychological and physical health correlates of body cell mass depletion among HIV+ men," Journal of Psychosomatic Research, vol. 49, no. 1 , pp. 55-57, 2000.

[13] D. P. Kotler, S. Burastero, J. Wang, and R. N. Pierson Jr., "Prediction of body cell mass, fat-free mass, and total body water with bioelectrical impedance analysis: effects of race, sex, and disease," The American Journal of Clinical Nutrition, vol. 64, supplement 3, pp. 489S-497S, 1996.

[14] M. Ott, H. Fischer, H. Polat et al., "Bioelectrical impedance analysis as a predictor of survival in patients with human immunodeficiency virus infection," Journal of Acquired Immune Deficiency Syndromes and Human Retrovirology, vol. 9, no. 1, pp. 20-25, 1995.

[15] Kennedy, A. Ramsay, L. Uiso, J. Gutmann, F. I. Ngowi, and S. H. Gillespie, "Nutritional status and weight gain in patients with pulmonary tuberculosis in Tanzania," Transactions of the Royal Society of Tropical Medicine and Hygiene, vol. 90, no. 2, pp. 162-166, 1996.

[16] N. I. Paton, L. R. Castello-Branco, G. Jennings et al., "Impact of tuberculosis on the body composition of HIV-infected men in Brazil," Journal of Acquired Immune Deficiency Syndromes and Human Retrovirology, vol. 20, no. 3, pp. 265-271, 1999.

[17] S. Shah, C. Whalen, D. P. Kotler et al., "Severity of human immunodeficiency virus infection is associated with decreased phase angle, fat mass and body cell mass in adults with pulmonary tuberculosis infection in Uganda," Journal of Nutrition, vol. 131, no. 11, pp. 2843-2847, 2001.

[18] R. Zachariah, M. P. Spielmann, A. D. Harries, and F. M. Salaniponi, "Moderate to severe malnutrition in patients with tuberculosis is a risk factor associated with early death," Transactions of the Royal Society of Tropical Medicine and Hygiene, vol. 96, no. 3, pp. 291-294, 2002.

[19] J. F. Burke, R. R. Wolfe, C. J. Mullany, D. E. Mathews, and D. M. Bier, "Glucose requirements following burn injury. Parameters of optimal glucose infusion and possible hepatic and respiratory abnormalities following excessive glucose intake," Annals of Surgery, vol. 190, no. 3, pp. 274-285, 1979.

[20] D. H. Elwyn, F. E. Gump, H. N. Munro, M. Iles, and J. M. Kinney, "Changes in nitrogen balance of depleted patients with increasing infusions of glucose," The American Journal of Clinical Nutrition, vol. 32, no. 8, pp. 1597-1611, 1979.

[21] S. J. Streat, A. H. Beddoe, and G. L. Hill, "Aggressive nutritional support does not prevent protein loss despite fat gain in septic intensive care patients," Journal of Trauma, vol. 27, no. 3, pp. 262-266, 1987.

[22] D. A. de Luis Roman, P. Bachiller, O. Izaola et al., "Nutritional treatment for acquired immunodeficiency virus infection using an enterotropic peptide-based formula enriched with n3 fatty acids: a randomized prospective trial," European Journal of Clinical Nutrition, vol. 55, no. 12, pp. 1048-1052, 2001.

[23] S. N. Shaw, D. H. Elwyn, J. Askanazi, M. Iles, Y. Schwarz, and J. M. Kinney, "Effects of increasing nitrogen intake on nitrogen balance and energy expenditure in nutritionally depleted adult patients receiving parenteral nutrition," The American Journal of Clinical Nutrition, vol. 37, no. 6, pp. 930-940, 1983.

[24] P. D. Greig, D. H. Elwyn, J. Askanazi, and J. M. Kinney, "Parenteral nutrition in septic patients: effect of increasing nitrogen intake," The American Journal of Clinical Nutrition, vol. 46, no. 6, pp. 1040-1047, 1987.

[25] C. B. Geibig, J. P. Owens, J. M. Mirtallo, D. Bowers, M. Nahikian-Nelms, and P. Tutschka, "Parenteral nutrition for marrow transplant recipients: evaluation of an increased nitrogen dose," Journal of Parenteral and Enteral Nutrition, vol. 15, no. 2, pp. 184-188, 1991.

[26] W. L. Macias, K. J. Alaka, M. H. Murphy, M. E. Miller, W. R. Clark, and B. A. Mueller, "Impact of the nutritional regimen on protein catabolism and nitrogen balance in patients with acute renal failure," Journal of Parenteral and Enteral Nutrition, vol. 20, no. 1, pp. 56-62, 1996.

[27] J. K. Shabert, C. Winslow, J. M. Lacey, and D. W. Wilmore, "Glutamine-antioxidant supplementation increases body cell mass in AIDS patients with weight loss: a randomized, doubleblind controlled trial," Nutrition, vol. 15, no. 11-12, pp. 860864, 1999.

[28] S. B. Williams, G. Bartsch, N. Muurahainen, G. Collins, S. S. Raghavan, and D. Wheeler, "Protein intake is positively associated with body cell mass in weight-stable HIV-infected men," Journal of Nutrition, vol. 133, no. 4, pp. 1143-1146, 2003.

[29] D. P. Kotler, A. R. Tierney, J. Wang, and R. N. Pierson Jr., "Magnitude of body-cell-mass depletion and the timing of death from wasting in AIDS," The American Journal of Clinical Nutrition, vol. 50, no. 3, pp. 444-447, 1989. 
[30] R. T. Chlebowski, M. B. Grosvenor, N. H. Bernhard, L. S. Morales, and L. M. Bulcavage, "Nutritional status, gastrointestinal dysfunction, and survival in patients with AIDS," American Journal of Gastroenterology, vol. 84, no. 10, pp. 12881293, 1989.

[31] U. Suttmann, J. Ockenga, O. Selberg, L. Hoogestraat, H. Deicher, and M. J. Muller, "Incidence and prognostic value of malnutrition and wasting in human immunodeficiency virusinfected outpatients," Journal of Acquired Immune Deficiency Syndromes and Human Retrovirology, vol. 8, no. 3, pp. 239246, 1995.

[32] A. Schwenk, A. Beisenherz, K. Romer, G. Kremer, B. Salzberger, and M. Elia, "Phase angle from bioelectrical impedance analysis remains an independent predictive marker in HIV-infected patients in the era of highly active antiretroviral treatment," The American Journal of Clinical Nutrition, vol. 72, no. 2, pp. 496-501, 2000.

[33] D. A. Wheeler, C. L. Gibert, C. A. Launer et al., "Weight loss as a predictor of survival and disease progression in HIV infection. Terry Beirn community programs for clinical research on AIDS," Journal of Acquired Immune Deficiency Syndromes and Human Retrovirology, vol. 18, no. 1, pp. 80-85, 1998. 


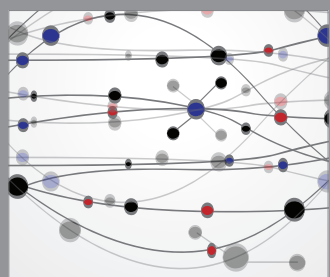

The Scientific World Journal
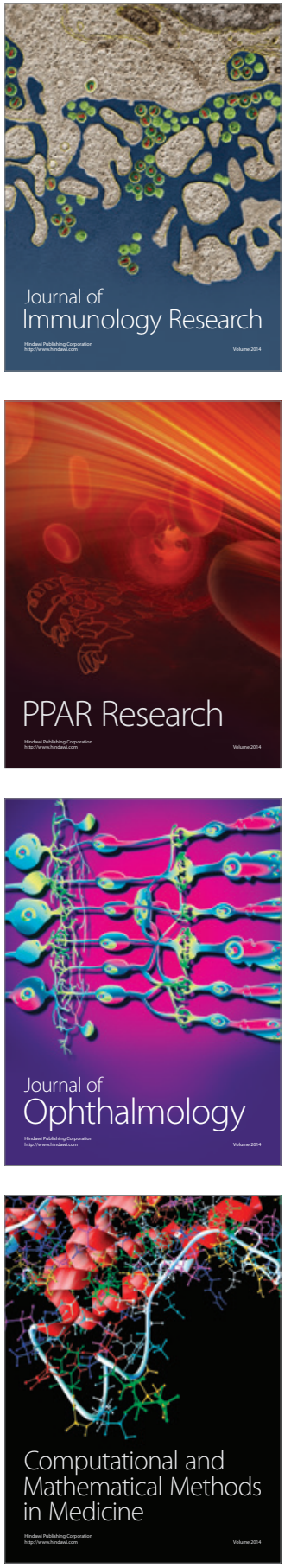

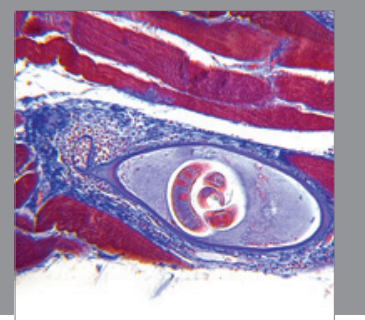

Gastroenterology

Research and Practice
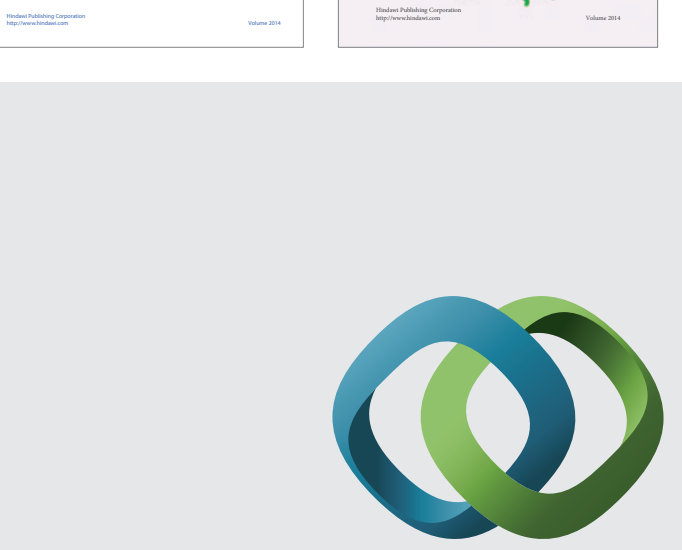

\section{Hindawi}

Submit your manuscripts at

http://www.hindawi.com
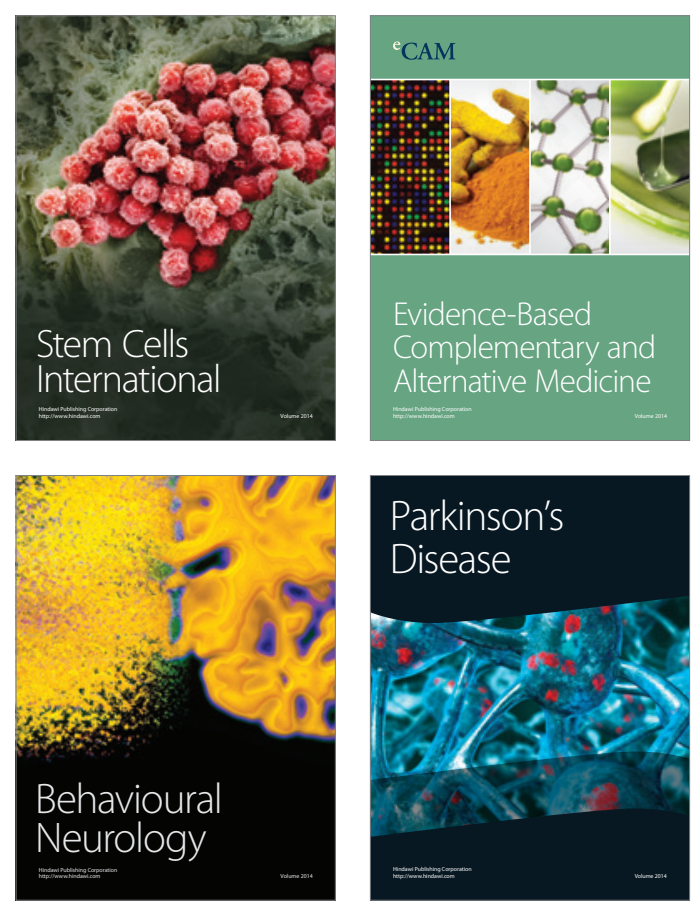

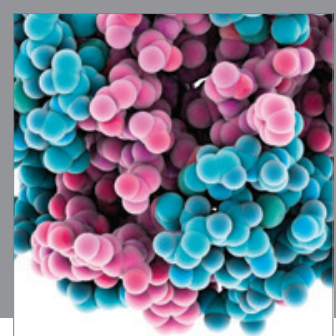

Journal of
Diabetes Research

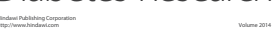

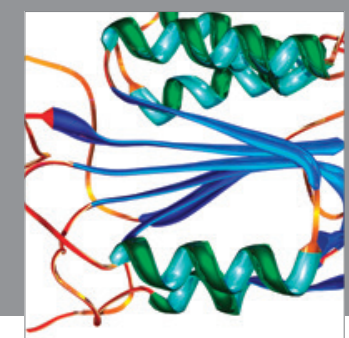

Disease Markers
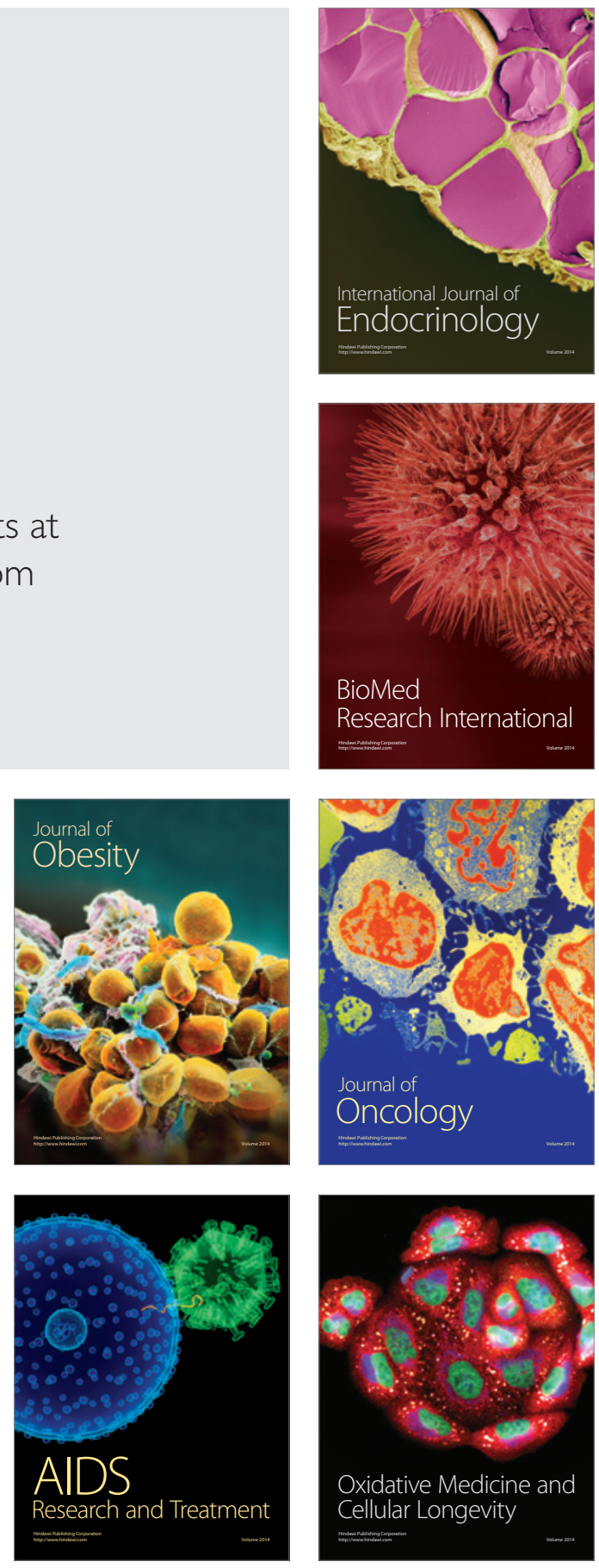